\title{
Hyperthermia Dosing and Depth of Effect
}

\author{
Oliver Szasz ${ }^{1}$, Gyula Peter Szigeti², Tamas Vancsik ${ }^{3}$, Andras Szasz ${ }^{1}$ \\ ${ }^{1}$ Department of Biotechnics, St. Istvan University, Budapest, Hungary \\ ${ }^{2}$ Institute of Human Physiology and Clinical Experimental Research, Semmelweis University, Budapest, Hungary \\ ${ }^{3}$ Department of Pathology and Experimental Cancer Research, Semmelweis University, Budapest, Hungary \\ Email: biotech@gek.szie.hu
}

How to cite this paper: Szasz, O., Szigeti, G.P., Vancsik, T. and Szasz, A. (2018) Hyperthermia Dosing and Depth of Effect. Open Journal of Biophysics, 8, 31-48. https://doi.org/10.4236/ojbiphy.2018.81004

Received: November 15, 2017

Accepted: January 20, 2018

Published: January 23, 2018

Copyright $\odot 2018$ by authors and Scientific Research Publishing Inc. This work is licensed under the Creative Commons Attribution International License (CC BY 4.0).

http://creativecommons.org/licenses/by/4.0/

\begin{abstract}
The penetration depth in the electromagnetic heating could be a crucial factor of its application, when the deep heating is the goal. The capacitive coupling is one of the most popular heating techniques in radiofrequency (RF) heating applications. The matching of the target defines the penetration possibilities. The current matched solution has deeper mathematically defined penetration in RF region than the capacitive plane-wave solution. The same power of application request high voltage with relatively low current for plane-wave inducing, while in current matching it has low voltage with high current. The effective depth of the action in the two solutions do not identical, the penetration defined by the intensity of $1 / \mathrm{e}$ portion of the incident beam is higher in the current-matched techniques.
\end{abstract}

\section{Keywords}

Oncothermia, Capacitive Coupling, Plane-Wave Matching, Current Matching, Penetration-Depth

\section{Introduction}

Despite its long history and some sophisticated electromagnetic energy transfer, hyperthermia remained a heavily debated topic in oncology. The fairly straightforward heating idea is realized with complicated machinery delivering the energy with hope to selectively eliminate or at least inactivate the malignant processes. The selection is one of the key-points, rock-build on the special heat sensitivity of cancerous cells.

However, the reality is more complex than could be solved by a simply focused heating on the tumor. Results are controversial despite the significant peaks of enthusiastic periods. Numerous phase II and phase III studies prove the positive effects of hyperthermia in combination with gold-standard therapies 
mostly with chemo- and/or radiotherapies [1] [2] [3]. The highest peak of success was the complementary hyperthermia plus radiotherapy Phase III trial for pelvic tumors, published in The Lancet [4]. The effective doubling of four-year survival by the combined therapy was exciting. However, the repeated study was unsuccessful [5]. A recent interim report of the newest cervix study shows no benefit of the radio-thermotherapy compared to the standard radiochemotherapy combination [6]. Problems counterwork the acceptance of hyperthermia even in its strongest field, the cervix cancer too.

The shadow of the actual problems appeared much earlier. The complementary radio-thermotherapy produced excellent local control for breast [7] and superficial tumors [8]. However, the overall survival significantly contradicted to the local control; it was worst when hyperthermia was involved in the treatments. Skepticism and refusing of hyperthermia was supported by the problem of toxicity when hyperthermia is complementary applied to radiotherapy [9].

The reason of the controversies looks simple: the thermal homeostatic feedback mechanisms induce higher blood flow to cool down the overheated volume. The effect of this could hamper the intended elimination of malignant cells because of the blood-stream supplies new, extra glucose for their support. Starts a non-controlled competition of the eliminative and supportive effects, and the result becomes accidental, but this is not all the challenges. The high blood flow significantly increases the risk of malignant invasion of cancer cells and the gain of metastases by their dissemination.

The robust number of positive results of hyperthermia in oncology need stabilization, must not be hindered by also many controversial experiences. One of the first explanations of the failure in cervix was the missing reference point [10], which in simple meaning is the unfixed technical background of the treatments. The well-focused heat-absorption on the tumor volume does not keep the temperature rise locally there. The temperature is naturally spreading by heat-conduction, and the heat is distributed very efficiently with convective transport through such a good heat-exchanger like the blood-stream. Professionals expect such technical solution, which heats the cancer cells alone by a large preciosity but does induce only moderate growth of the blood-flow, avoid its adverse effect. They would like to see however some increase of blood flow to the tumor, which gains the drug perfusion and increases its efficacy locally, together with the higher oxygen content for the sensitizing the radiotherapy in adjunct combination. These demands look contradictory, but it has realistic solution [11]. The conventional hyperthermia focuses on the tumor mass, which will heat up the tumor cells anywhere inside. We should make different heating philosophy. The trick is the accurate selection of the cancerous cells alone, heat them up, and their heat will raise the temperature of the entire tumor mass, Figure 1. The trick allows high enough temperature on the chosen cells while the temperature would be moderate in the whole mass of tumor. This type of treatment exists in research [12] and clinical applications [13]. It is named 


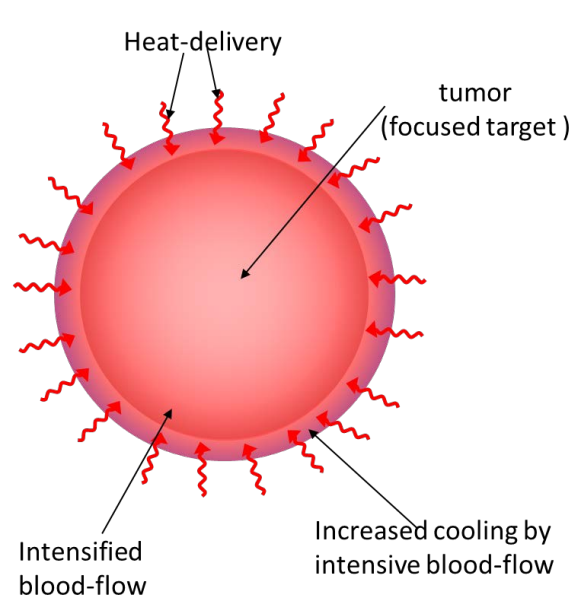

(a)

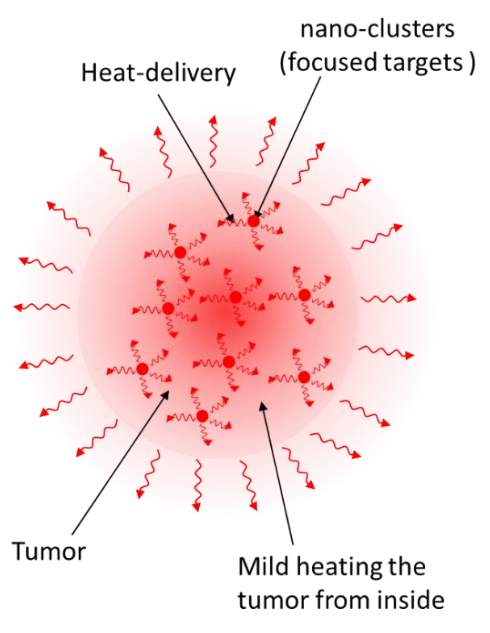

(b)

Figure 1. (a) Tumor-mass heat intensive blood flow around; (b) Tumor-cell heatblood-flow medium. The nano-targets are the membrane rafts of malignant cells.

"nanothermia" [14], due to its particular effect a membrane rafts of malignant cells which are in size of nanoscopic range [15].

The newest achievements of oncological hyperthermia are connected to the immune effects. The local hyperthermia acts of course locally when it is not combined with other methods. The malignancy however only looks local, but it is not such. It is malignant producing numerous systemic effects by the free circulation malignant cells in the blood stream. The consequences are micrometastases which represent the most of the fatalities when growing to recognizable size. The solution of extension the local treatment to systemic has an example in radiation therapy, where the abscopal effect (effect far away from the treatment area) was observed more than half century ago, [16]. Intensive research on the systemic effects started later [17]. This trend continues, and its connection with the immune system became the central task of the research, [18] [19].

The similar examination also started in various applications of hyperthermia research. Observations with the radiofrequency ablation [20] were promising, and at the end, a complete book was devoted to the topic [21].

This abscopal effect has a close attention presently in the oncologic hyperthermia too, [22]. The expected mechanism starts with apoptosis, [23]; which happens through immunogenic cell death [24], probably responsible for tumor-specific immune reaction, [25].

\section{Methods}

Local-regional hyperthermia has various technical solutions. These solutions mostly work on electromagnetic principles in four main categories: e.g. magnetic, electric, radiative and galvanic [26], Figure 2.

The coupling strength, which is the efficacy of the absorption of electromagnetic energy in the target increases from magnetic to galvanic, Figure 3 . The 


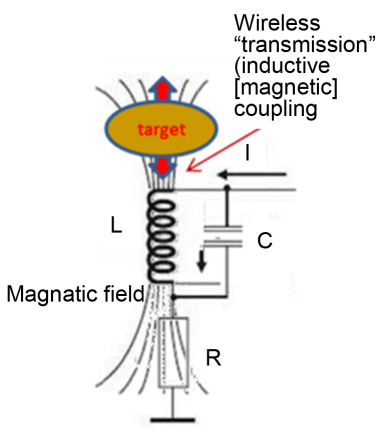

(a)

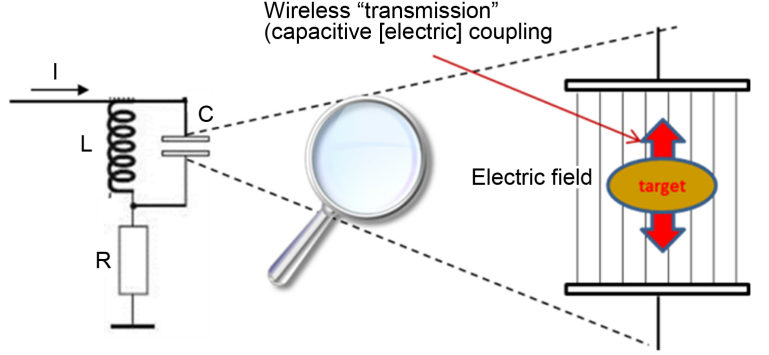

(b)

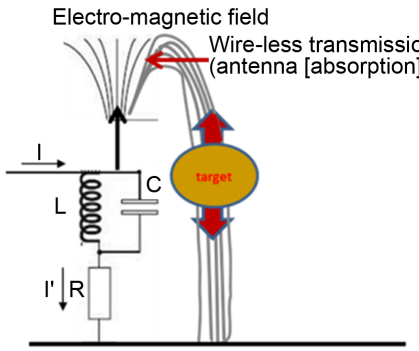

(c)

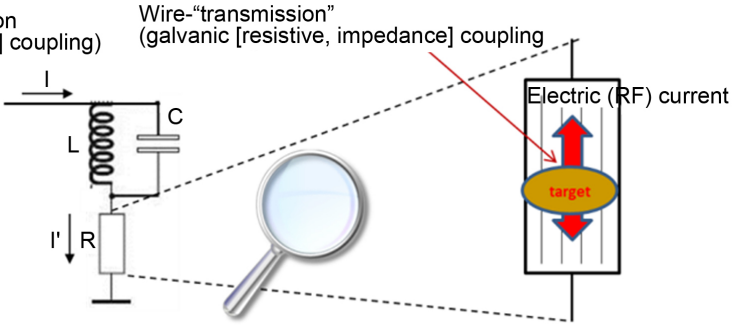

(d)

Figure 2. The four basic technical solutions for deep heating with electromagnetic effects. The inductive (a), capacitive (b), radiative (c) and galvanic (d).

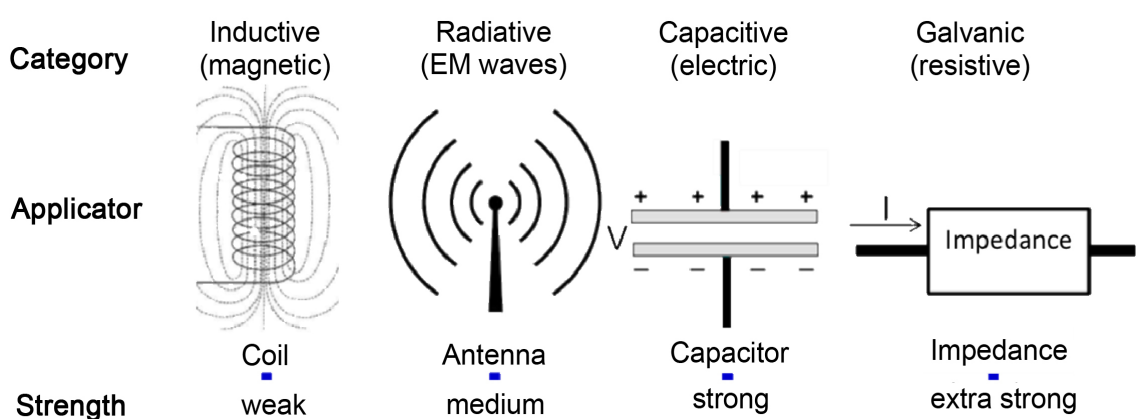

Figure 3. The strength of coupling of various energy transfer methods in the radiofrequency range of $1-15 \mathrm{MHz}$ frequency. Comparison is with the same output power at same frequency in biological materials. The weak interaction is Eddy current and spin-interactions due to the missing ferromagnetic materials, the medium is the energy-loss of the absorbed waves, the strong uses dielectric loss with electric field, while the extra-strong is a compulsory current by galvanic contacts, producing Joule-heat.

direction of technical development was from strong to weak couplings, starting with galvanic (direct galvanic contact with the target [27]), and it rapidly developed the new methods by growing frequencies [28] [29]. The new considerations developed the concept of biologically closed electric circuits, [30] [31]. This theory triggered multiple applications in strong coupling procedures [32] [33], [34]. This strong energy-absorption developed such invasive hyperthermia methods like interstitial hyperthermia [35] and also the application of direct ablation [36] [37].

Weak coupling like the magnetic field needs additional, artificial absorbers for 
ingestion. Ferromagnetic materials, seeds, nanoparticles, etc. help the adequate energy intake.

The strength of coupling affects the applied dose and control of the process. When the coupling is strong, we may approximate the complete absorption of the provided energy by the actual device which output power can control the dosing. However, in the weak coupling, this assumption of full absorption does not work. The provided energy dose should be monitored independently. The independent control needs extra information from the target, which is usually real-time temperature measurement.

The temperature control has enormous technical complications. The correct temperature measurement is invasive but gives information only to a point where the sensor is located. Having spatial distribution has to be inserted many invasive sensors into the target, which is a too high risk in the medical practice. The non-invasive temperature measurement has numerous drawbacks. The most common non-invasive method is the application of infrared thermometers or cameras, which can control the temperature precisely, but only on the surface of the target. The noninvasive radiometry methods need a multi frequency solution to deep-scanning, which is a great technical challenge. The specialized MRI techniques measure the temperature inaccurately, mix the changes complexly by chemical rearrangements with the effects of temperature in the measured volume.

Avoid the complications of the temperature measurement choose the strong coupling offers an ideal solution to measure the absorbed energy. Unfortunately, it also has a disadvantage; the absorbed heat energy does not remain there where we initially intended it. The intensified blood-flow takes away the majority of the heat, and so the energy-absorption and the temperature do not correlate in the target. The solution of it is the right and selective nanoheating like we discussed it above.

Consequently, the perfect dose concept has to contain the strong coupling and the precise nanoscopic selection. Technically it is not a simple task. For strong coupling, we need a galvanic arrangement, but its direct use when the energy is high enough to heat up the target causes particular risk of burn directly on the top of the skin, or deeper in adipose layers. Avoid this disadvantage a combination of capacitive and galvanic coupling offers the ideal solution.

The precise impedance matching arrangement involves special structure and well-chosen materials of the electrodes as well as high accuracy tuning with proper compensation of the capacitive factor of the actual loading impedance. This situation allows approaching the radio-frequency (RF) current density calculations instead of the plane wave approximation. Nevertheless, the certainly near-field situation does not permit waves in the applied tight electrode connection Figure 4.

The calculation of the current flow points the same current in the entire serial circuit, including the load, which is the treated local volume of a patient, Figure 5. 


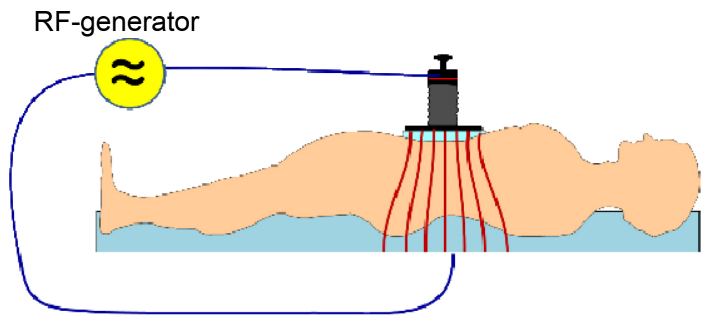

(a)

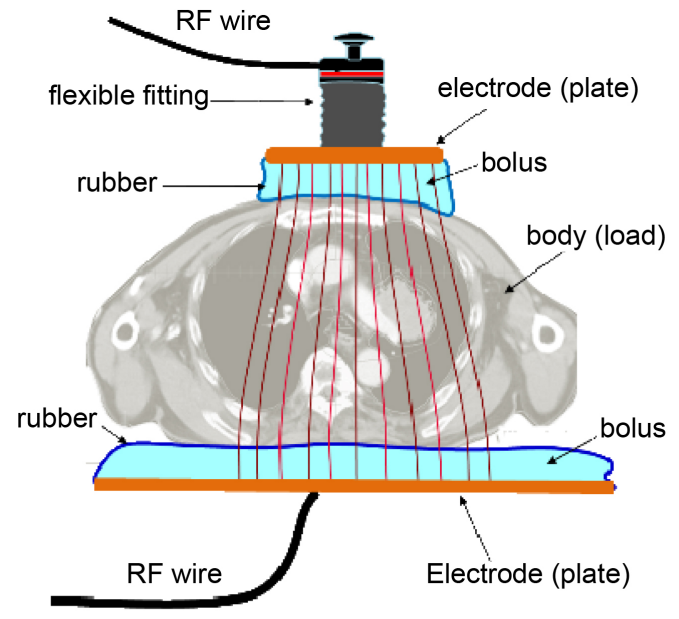

(b)

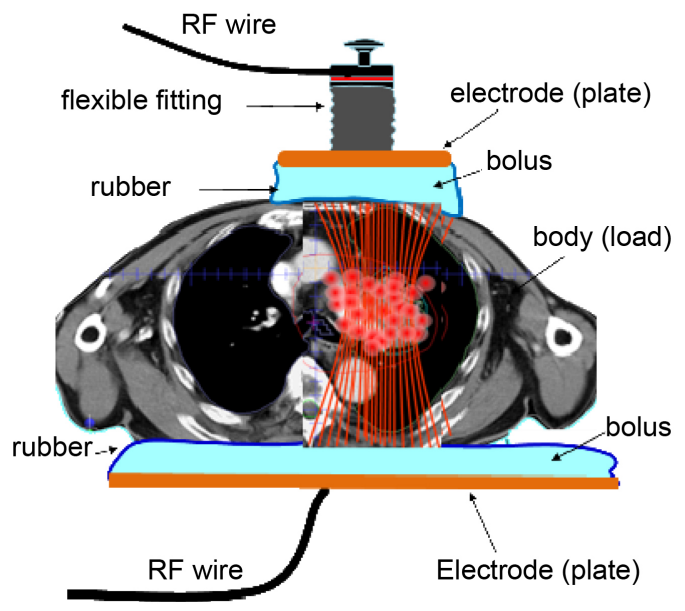

(c)

Figure 4. Schematic view of the current flow in the treated body (a) homogenous assumption, no selection of the tumor-tissue (the frequency of the current is higher than $15 \mathrm{MHz}$ ), (b), automatic focusing by electric conductivity, the frequency is lower than 15 $\mathrm{MHz}$ (c).

The size of an arbitrary area in depth $(h-x)$ is:

$$
A(x)=\pi\left(\frac{D}{2}+y\right)^{2}=\left[\frac{D}{2}+(h-x) \cdot \operatorname{tg} \alpha\right]^{2} \pi
$$

Moreover, we know, that the total sum of the current in every depth is equal, 

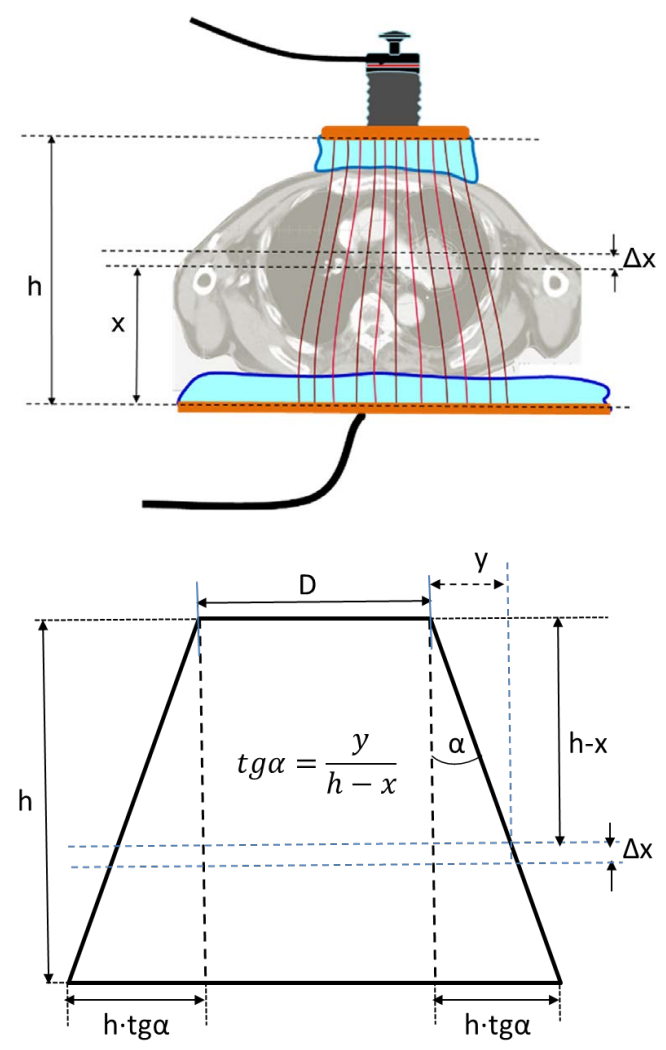

Figure 5. $h=$ distance between the electrodes; $x=$ arbitrary depth in the target; $\Delta x=$ thickness of a slide in the target (homogeneous approximation).

which electric current starts on the top, arrives at the bottom. However, only the density of the current will be less due to the widening of its distribution. The value of the integral of the actual current density in the investigated slide of the target must be the same as the input current is. When the input current is $I$, the electric current density in arbitrary depth is:

$$
j(x)=\frac{I}{A(x)}=\frac{I}{\left(\frac{D}{2}+\operatorname{tg} \alpha(h-x)\right)^{2} \pi}
$$

The integral of the current density is any parallel areas with the electrodes in plane-parallel capacitive coupling has a stationer situation, constant in any depth:

$$
I=\int_{\text {parallel }} \underline{j} \underline{\mathrm{S}}=\text { stationery }
$$

With this, the value of SAR for an arbitrary $x$ location in the homogeneous media with specific resistance of $\rho$ (reciprocal value of conductivity $\sigma$ ) is

$$
\rho_{m} \operatorname{SAR}(x)=\frac{1}{2} \rho|j(x)|^{2}=\frac{1}{2} \rho \frac{|I|^{2}}{\left[\left(\frac{D}{2}+\operatorname{tg} \alpha(h-x)\right)^{2} \pi\right]^{2}}
$$


where $\rho_{m}$ is the mass density. For calculation of the current, we introduce the substitution of the layer with the discrete electric circuit Figure 6.

The impedance of the equivalent circuit can be expressed as

$$
\begin{aligned}
\Delta Z(x) & =\frac{\frac{1}{i \omega \Delta C(x)} \Delta R(x)}{\frac{1}{i \omega \Delta C(x)}+\Delta R(x)}=\frac{\Delta R(x)}{1+i \omega \tau(x)} \\
& =\frac{1}{1+i \omega \tau(x)} \frac{\rho(x)}{\left(\frac{D}{2}+\operatorname{tg} \alpha(h-x)\right)^{2} \pi} \mathrm{d} x, \\
\tau(x)=\Delta R \Delta C=\rho(x) \varepsilon(x) &
\end{aligned}
$$

where $\rho(x)=1 / \sigma(x)$ is the specific resistance and $\varepsilon(x)$ is the permittivity of dielectric material in depth $x$. The function $\tau(x)$ is the time-constant in this depth.

The impedance $\tilde{Z}_{h}$ of the arrangement is:

$$
\tilde{Z}_{h}=\int_{0}^{h} \frac{\rho(x)}{\left(\frac{D}{2}+\operatorname{tg} \alpha(h-x)\right)^{2}(1+i \omega \tau(x)) \pi} d x
$$

Consequently, the voltage of the RF source $U_{0}$ determines the electrode current, like $I=\frac{U_{0}}{\tilde{Z}_{h}}$.

The impedance when the target is homogeneous:

$$
Z_{h}=\frac{\rho}{(1+i \omega \tau) \pi} \int_{0}^{h} \frac{1}{\left(\frac{D}{2}+\operatorname{tg} \alpha(h-x)\right)^{2}} \mathrm{~d} x=\frac{4 \rho h \operatorname{tg} \alpha(1-i \omega \tau)}{\pi D\left(1+(\omega \tau)^{2}\right)(D+2 h \operatorname{tg} \alpha)}
$$

and the current is

$$
I=\frac{U_{0}}{Z_{h}}=U_{0} \frac{\pi D(D+2 h \operatorname{tg} \alpha)}{4 \rho h \operatorname{tg} \alpha}(1+i \omega \tau)
$$

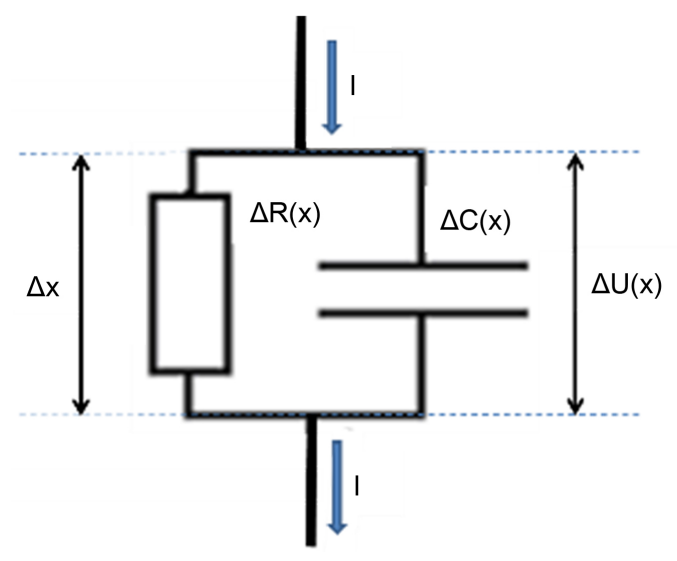

Figure 6. The equivalent circuit of a layer with $\Delta x$ thickness (discrete substitution). 
From where the phase $(\delta$ ) angle between the voltage and current is

$$
\operatorname{tg} \delta=-\omega \tau
$$

The impedance has also a stationery behavior, due to its Fermat principle refraction on internal boundary change.

$$
\begin{aligned}
& E_{t 1}=E_{t 2} \\
& E_{n 1} \operatorname{tg} \Theta_{1}=E_{n 2} \operatorname{tg} \Theta_{2} \\
& \frac{E_{n 1}}{E_{n 2}}=\frac{\operatorname{tg} \Theta_{2}}{\operatorname{tg} \Theta_{1}}=\frac{\sigma_{2}+j \omega \varepsilon_{2}}{\sigma_{1}+j \omega \varepsilon_{1}}
\end{aligned}
$$

So

$$
\left(\sigma_{1}+j \omega \varepsilon_{1}\right) \operatorname{tg} \Theta_{1}=\left(\sigma_{2}+j \omega \varepsilon_{2}\right) \operatorname{tg} \Theta_{2}=C
$$

OR

$$
\rho_{2}=\rho_{1} \frac{\operatorname{tg} \Theta_{1}}{\operatorname{tg} \Theta_{2}}
$$

The impedance in a branch has similar behavior, having cross-sectional surface $A_{1}$ have refraction and turns into a branch cross-section. The lengths of the branches are $l_{1}$ and $l_{2}$, and their angles to the surface normal-vector are $\Theta_{1}$ and $\Theta_{2}$, Figure 7. The average specific impedances in the branches are $\bar{\rho}_{1}=\left(\sigma_{1}+i \omega \varepsilon_{1}\right)^{-1}$ and $\bar{\rho}_{2}=\left(\sigma_{2}+i \omega \varepsilon_{2}\right)^{-1}$.

Than the impedance of the refracted branch is

$$
\bar{Z}=\bar{\rho}_{1} \frac{l_{1}}{A_{1}}+\bar{\rho}_{2} \frac{l_{2}}{A_{2}}=\bar{\rho}_{1} \frac{l_{1}}{A \cos \Theta_{1}}+\bar{\rho}_{2} \frac{l_{2}}{A \cos \Theta_{2}}
$$

From the Figure 7:

$$
\begin{aligned}
& l_{1}=x \sin \Theta_{1} \\
& l_{2}=(l-x) \sin \Theta_{2}
\end{aligned}
$$

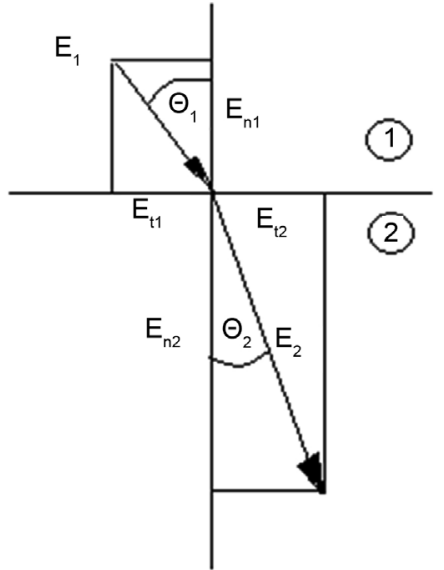

(a)

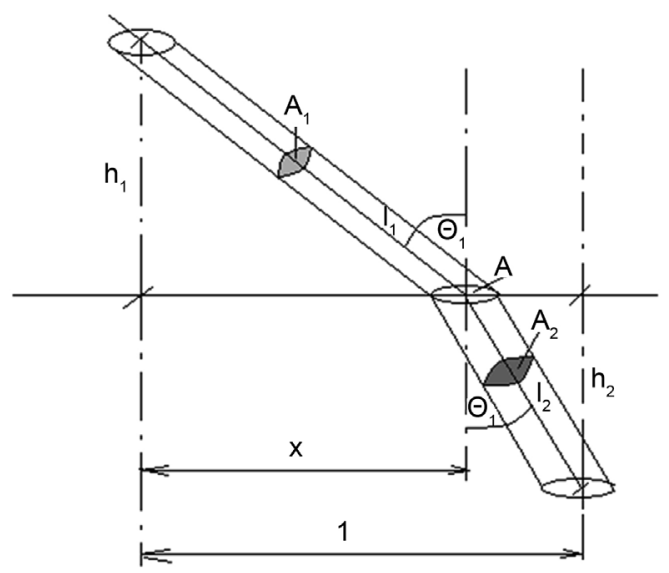

(b)

Figure 7. (a) Vectorial refraction of the electric-field vector; (b) The impedance refraction at the boundary of media shown in electric field "branch". 
Hence

$$
Z=\frac{\rho_{1}}{A} l \operatorname{tg} \Theta_{1}=\frac{C}{A} l
$$

This means, that the integral of $\bar{Z}$ is constant, the impedance is stationery like the current is.

$$
Z=\int \frac{\rho}{A} \mathrm{~d} l=\text { stationery }
$$

Which works like a Fermat-principle:

$$
Z=\int n \mathrm{~d} l=\text { stationery } \text { where } n=\frac{\rho}{A}
$$

When the conductive effect dominant we have simple conditions from (10),

$$
\sigma_{1} \operatorname{tg} \Theta_{1}=\sigma_{2} \operatorname{tg} \Theta_{2}=C^{\prime}
$$

From the stationery behavior of the RF-current flowing through the patient the spreading of electric field and depends on the starting angle of the complete line of the field. This is formulated with a difference equation we get:

$$
\Delta r=\frac{\sigma\left(r_{0}, z=0\right) \operatorname{tg} \Theta_{0}}{\sigma(r, z)} \Delta z
$$

where $\sigma\left(r_{0}, z=0\right)$ is the conductivity at the place of input, and $\operatorname{tg} \Theta_{0}$ is the slope of the input.

The spreading in homogeneous media is less than one radius of the upper electrode when the starting input angle is limited to the well-arranged plan-parallel capacitive coupling. So

$$
\operatorname{tg} \alpha \leq \frac{D}{2 h}
$$

\section{Results}

The matching quality of the system depends on the real energy-absorption in the load (patients), so the admittance would be as much as possible clean conductance., Inductivity $\left(L_{h}\right)$ is used in serial circuit to compensate of the system susceptance creating resonance at frequency $f=\frac{\omega}{2 \pi}$ :

$$
L_{h}=-\frac{4 \tau \rho h \operatorname{tg} \alpha}{\pi D\left(1+(\omega \tau)^{2}\right)(D+2 h \operatorname{tg} \alpha)}
$$

The penetration depth by its definition is when the original incident field decays to $1 / e(\sim 37 \%)$ and the energy decreases to $1 / e^{2}(\sim 13 \%)$. Due to the electric field is proportional with the current-density $(\underline{j})$ and the energy is with the square of it, the penetration depth of the current density when the system is well matched in resonance with the load will be when the $\underline{j}$ decreases to $13 \%$, $\left(1 / e^{2}\right)$, which corresponds to the decrease of SAR to $13 \%$. The input current density from (2) is $4 I / D^{2} \pi$, and the input and the value at the penetration depth of 
SAR from (3) is

$$
S A R_{0}=\frac{1}{2} \rho \frac{4|I|^{2}}{\left[D^{2} \pi\right]^{2}} \text { and } S A R_{p}=\frac{1}{e^{2}} \rho \frac{2|I|^{2}}{\left[D^{2} \pi\right]^{2}}
$$

The penetration depth is counted from the top of the body, so $\delta=h-x$. Consequently, the penetration depth of energy by definition using (3) is

$$
\delta_{S A R}=\frac{D}{\operatorname{tg} \alpha}\left(\sqrt{\frac{e}{2}}-\frac{1}{2}\right) \cong \frac{0.67 D}{\operatorname{tg} \alpha}
$$

while the penetration for the current density using (2) is

$$
\delta_{j}=\frac{D}{2 \operatorname{tg} \alpha}(\sqrt{e}-1) \cong \frac{0.32 D}{\operatorname{tg} \alpha}
$$

The penetration does not depend on the size of the electrode. Using the limit of (19), we get:

$$
\begin{aligned}
& \delta_{\text {SAR }} \geq 1.34 h \\
& \delta_{j} \geq 0.64 h
\end{aligned}
$$

This penetration depends on the thickness of the patient instead of the size of the electrode. A calculation of the E-field lines by realistic inhomogeneous case shows a spreading less than the limit in (19), Figure 8.

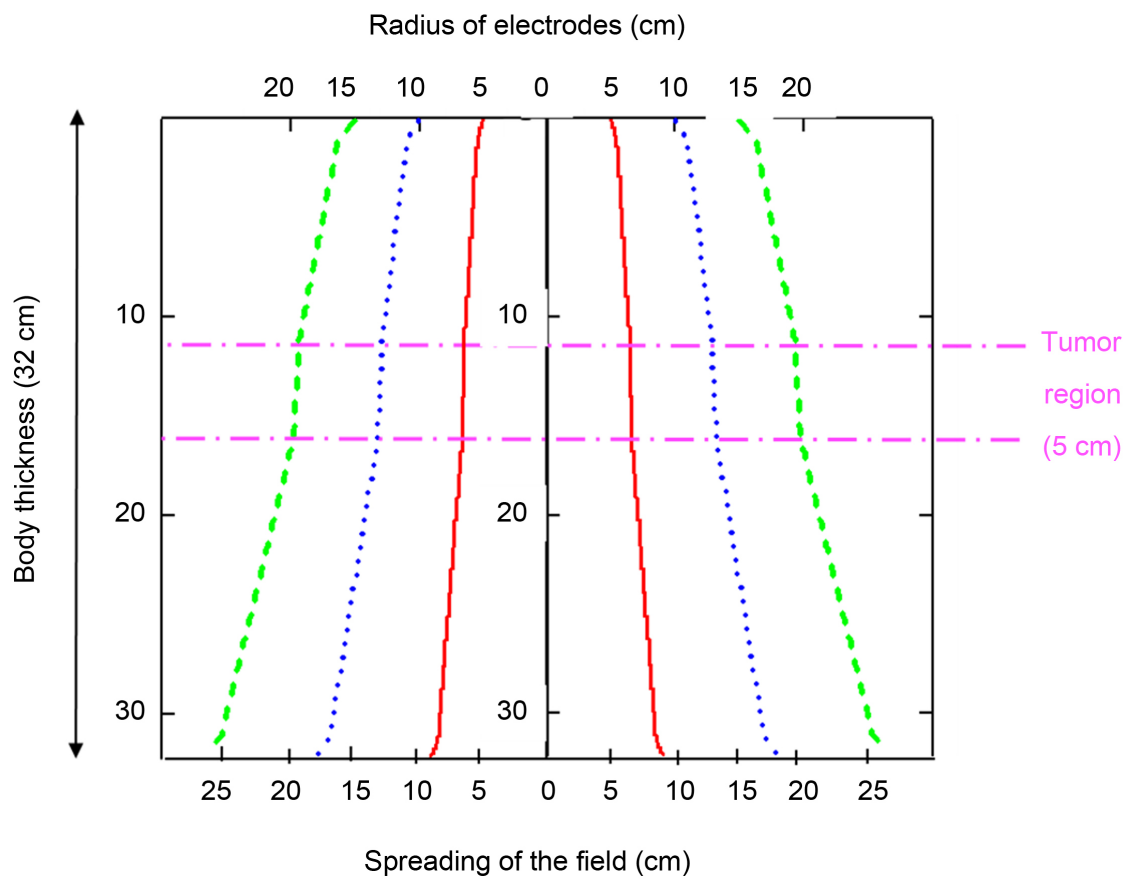

Figure 8. Spreading of current in depth of the body. The chosen parameters are: Body-thickness (average of adipose Caucasian) is $32 \mathrm{~cm}$, electrode diameters of usual applications are $10 \mathrm{~cm}(--), 20 \mathrm{~cm}(\bullet \bullet \bullet)$ and $30 \mathrm{~cm}(---)$. The dry skin on the top and bottom is $1 \mathrm{~cm}$ with $0.1 \mathrm{~S} / \mathrm{m}$ conductivity, the tumor is at $11 \mathrm{~cm}$ depth, and $5 \mathrm{~cm}$ thick, and has $1.5 \mathrm{~S} / \mathrm{m}$ conductivity average healthy tissue conductivity is 0.5 and $0.4 \mathrm{~S} / \mathrm{m}$ above and below the tumor, respectively (Data are averages from [38]). 
The radiative penetration depth defined by the planar-wave absorption [26] [39] is

$$
\delta_{p w}=\frac{1}{\omega\left[\frac{\varepsilon \mu}{2}\left(\sqrt{1+\left(\frac{\sigma}{\omega \varepsilon}\right)^{2}}-1\right)\right]^{1 / 2}}
$$

Does not depend on the thickness of the patients, but rely on the frequency and the material dielectric constant, as well as its conductivity. These parameters are irrelevant in RF-current-matching conduction only the focusing and the original energy deposit has importance.

\section{Discussion}

Hyperthermia treatment defined by the power and its efficacy to be absorbed in the target. Assuming the same effectiveness, the penetration depth varies by the size of electrodes in current matched capacitive coupling. The reason is, when the electrode has a larger surface, the impedance below it decreases, and so the same power has higher current and lower voltage in the ideal case. Due to the Ohm-law the current linearly depends on the electrode area as impedance changes according to (12); so the current density does not depend on the size of the electrode when the applied voltage is constant:

$$
I=\frac{U}{Z}=\frac{U}{l} \bar{\sigma} A \text { so } j=\frac{I}{A}=\frac{U}{l} \bar{\sigma}
$$

Consequently, from (27) and (3) the SAR also does not depend from the surface of the electrode. Using the values of $\operatorname{tg} \alpha$ from Figure 8. the penetration shows $\delta_{\text {SAR }}=53.6 \mathrm{~cm}$ and $\delta_{j}=25.6 \mathrm{~cm}$ independent of the size of the electrode, indeed.

Compare the penetration depths of the two kinds of capacitive coupling we have certain differences, Figure 9.

The current-matching $1 / e$ penetration is superior on the plane-wave matching, while both are capacitive coupling arrangements. The $1 / e^{2}$ penetration (energy scheme) has longer penetration in current-matching than the thickness of any patients with more than $50 \mathrm{~cm}$, which corresponds to $314 \mathrm{~cm}$ waist circumflex of the patient, which is not realistic.

The penetration depth defines a loss of the absorbed specific energy or field in the body. The $1 / e$ or the $1 / e^{2}$ means that below this penetration $37 \%$ or $13 \%$ of the field or energy remains and goes deeper. This penetration is a mathematical construction and does not determine the biological effects. The remained values of the acting field or absorbed energy could be enough to be effective for the expected actions. In biological point of view, this action defined depth describes the real penetration and not the mathematical one. A good example for this is the effect of X-rays causing apoptosis [40]. The mathematically defined penetration depth of the applied X-ray was around $10 \mathrm{~cm}$, but the apoptosis effect was growing afterward and was active even over $25 \mathrm{~cm}$ depths too. In the case of 


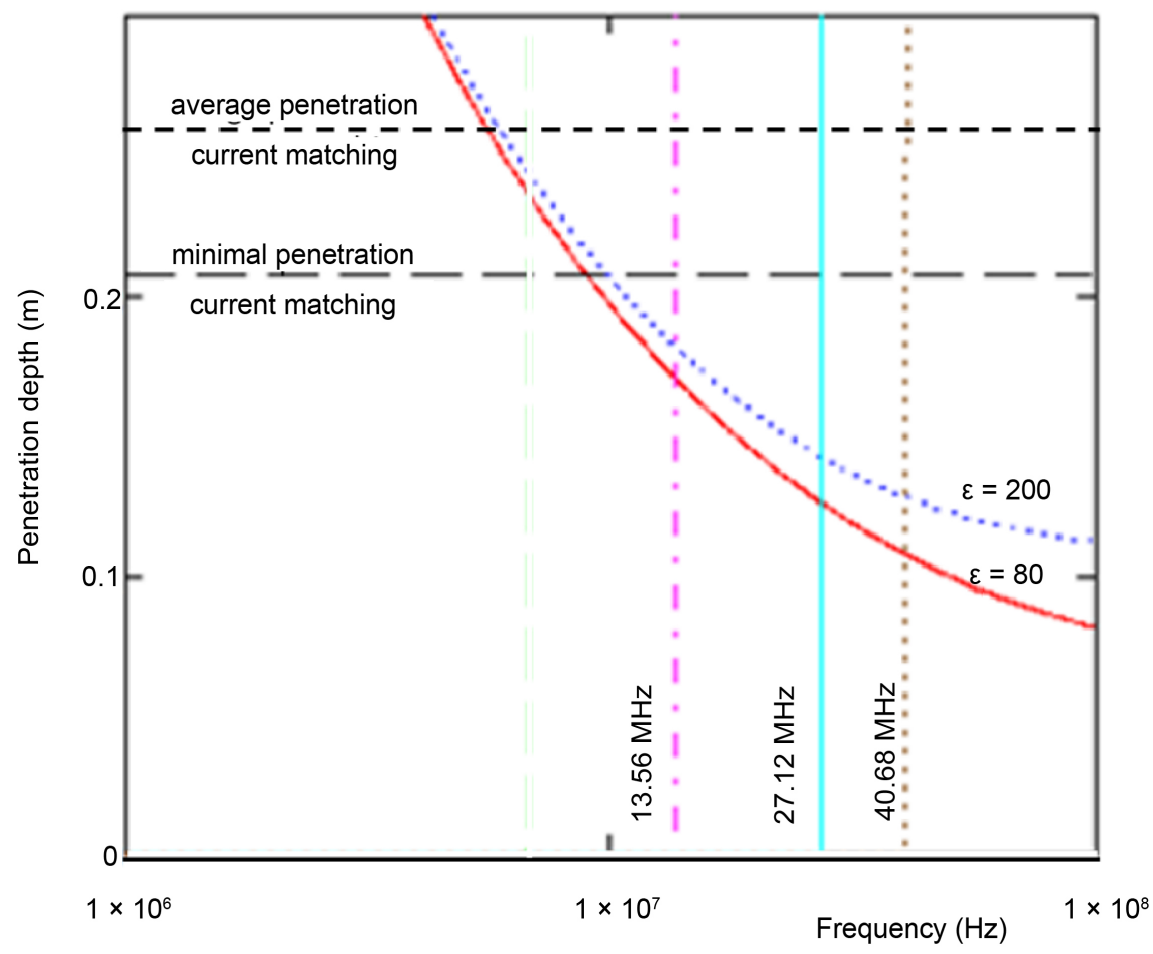

Figure 9. Comparison of penetration by current matching and plane-wave absorption. The definition is the $1 /$ e loss (34\% remains) of the initial energy. Vertical lines show the certified frequencies for medical use. The average conductivity is $0.6 \mathrm{~S} / \mathrm{m}$ in every case; the patient width is $32 \mathrm{~cm}$. The average penetration of current-matching is independent of the frequency.

capacitive coupling hyperthermia, two different concepts of effects are introduced. In the planar-wave matching, the direct heating and the necrotic cell-death (CEM $43^{\circ} \mathrm{CTx}$ dose) is expected. In temperature scale, the aim in this matching technology is to reach at least $43^{\circ} \mathrm{C}$ temperature in the $\mathrm{Tx}$ effective percentages of the tumor treatment. In the current-matching case, the goal is apoptosis and excitation of the actual membrane rafts [41] [42], initialize immunogenic cells death, [43]. The difference between the two matching methods in capacitive coupling techniques well observable and proven [44]. The apoptotic signal can be induced with much smaller energy (and field) than the necrotic [45], which is shown in the strict synergy of the heat and field effects [46].

The deep heating of the current density is proven by phantom measurements [47] as well as in the liver of living, anesthetized pig [48]. The efficacy in deep heating of the RF-current coupled hyperthermia is well applicable in the human medicine [49] [50], even in metastatic cases too [51], the technique of mEHT is highly efficient [26] [52], user-friendly, easy to operate and relatively cheap in comparison to other hyperthermia units [53] [54] [55].

\section{Conclusion}

The penetration depth in the capacitively coupled systems depends on the matching technique, [56]. It is a new paradigm in oncologic hyperthermia [57]. 
The RF-current matched solution has deeper mathematically defined penetration over the $\mathrm{MHz}$ frequency region than the plane-wave solution [14]. This last does not rely on the thickness of the patients, which the current matching does. The expected action in the body is also different in the two capacitive matching solutions. The current matching targets the apoptotic processes by immunogenic cell-death, while the plane-wave expects high temperature is causing necrosis of the heat-sensitive malignant cells. This method is well applied as complementary therapy [58], having special cellular effects [54], The electric field excites extrinsic apoptosis [59] [60] on the pathway starting at TRIAL-R2 (FADD-FAS) complex inducing cleaved caspase- 8 and the executor caspase- 3 makes the apoptosis [23]. The proapoptotic cell-death-related gene network (EGR1, JUN, CDKN1A) is elevated which is available only in mEHT [44]. The complete MAPK pathway (RAS $\rightarrow$ RAF $\rightarrow$ MEK $\rightarrow$ ERK), is also excited to the apoptotic processes [61]. The effective depth of the action does not look identical to the mathematical definition of the penetration. For apoptosis, the sufficient depth could be much deeper than for necrosis.

\section{Acknowledgements}

This work was supported by the Hungarian Competitiveness and Excellence Programme grant (NVKP_16-1-2016-0042).

\section{References}

[1] Falk, M.H. and Issels, R.D. (2001) Invited Review Hyperthermia in Oncology. International Journal of Hyperthermia, 17, 1-18. https://doi.org/10.1080/02656730150201552

[2] van der Zee, J. (2002) Heating the Patient: A Promising Approach? Annals of Oncology, 13, 1173-1184. https://doi.org/10.1093/annonc/mdf280

[3] Hildebrandt, B., Wust, P., Ahlers, O., Dieing, A., Sreenivasa, G., Kerner, T., Felix, R. and Riess, H. (2002) The Cellular and Molecular Basis of Hyperthermia Clinical Reviews in Oncology/Hematology, 43, 33-56.

[4] van der Zee, J., Gonzalez Gonzalez, D., van Rhoon, G.C., van Dijk, J.D., van Putten, W.L. and Hart, A.A., Dutch Deep Hyperthermia Group (2000) Comparison of Radiotherapy Alone with Radiotherapy plus Hyperthermia in Locally Advanced Pelvic Tumours: A Prospective, Randomised, Multicentre Trial. Lancet, 355, 1119-1125. https://doi.org/10.1016/S0140-6736(00)02059-6

[5] Vasanthan, A., Mitsumori, M., Park, J.H., Zeng, Z.F., Zhong, Y.B., Oliynychenko, P., Tatsuzaki, H., Tanaka, Y. and Hiraoka, M. (2005) Regional Hyperthermia Combined with Radiotherapy for Uterine Cervical Cancers: A Multiinstitutional Prospective Randomized Trial of the International Atomic Energy Agency. International Journal of Radiation Oncology * Biology * Physics, 61, 145-153. https://doi.org/10.1016/j.ijrobp.2004.04.057

[6] Lutgens, L.C., Koper, P.C., Jobsen, J.J., van der Steen-Banasik, E.M., Creutzberg, C.L., van den Berg, H.A., Ottevanger, P.B., van Rhoon, G.C., van Doorn, H.C., Houben, R. and van der Zee, J. (2016) Radiation Therapy Combined with Hyperthermia versus Cisplatin for Locally Advanced Cervical Cancer: Results of the Randomized RADCHOC Trial. Radiotherapy and Oncology, 120, 378-382. 
https://doi.org/10.1016/j.radonc.2016.02.010

[7] Vernon, C.C., Hand, J.W., Field, S.B., Machin, D., Whaley, J.B,, van der Zee, J., van Putten, W.L., van Rhoon, G.C., van Dijk, J.D., González González, D., Liu, F.F., Goodman, P. and Sherar, M. (1996) Radiotherapywith or without Hyperthermia in the Treatment of Superficial Localized Breast Cancer: Results from Five Randomized Controlled Trials. International Journal of Radiation Oncology Biology Physics, 35, 731-744. https://doi.org/10.1016/0360-3016(96)00154-X

[8] Jones, E.L., Oleson, J.R., Prosnith, L.R., Samulski, T.V., Vujaskovic, Z., Yu, D., Sanders, L.L. and Dewhirst, M.W. (2005) Randomized Trial of Hyperthermia and Radiation for Superficial Tumors. Journal of Clinical Oncology, 23, 3079-3085. https://doi.org/10.1200/JCO.2005.05.520

[9] Emami, B., Scott, C., Perez, C.A., Asbell, S., Swift, P., Grigsby, P., Montesano, A., Rubin, P., Curran, W., Delrowe, J., Arastu, H., Fu, K. and Moros, E. (1996) Phase III Study of Interstitial Thermoradiotherapy Compared with Interstitial Radiotherapy Alone in the Treatment of Recurrent or Persistent Human Tumours: A Prospectively Controlled Randomized Study by the Radiation Therapy Oncology Group. International Journal of Radiation Oncology Biology Physics, 34, 1097-1104. https://doi.org/10.1016/0360-3016(95)02137-X

[10] Fatehi, D., van der Zee, J., van der Wal, E., et al. (2006) Temperature Data Analysis for 22 Patients with Advanced Cervical Carcinoma Treated in Rotterdam Using Radiotherapy, Hyperthermia and Chemotherapy: A Reference Point Is Needed. International Journal of Hyperthermia, 22, 353-363.

https://doi.org/10.1080/02656730600715796

[11] Szasz, A. (2013) Challenges and Solutions in Oncological Hyperthermia. Thermal Medicine, 29, 1-23. https://doi.org/10.3191/thermalmed.29.1

[12] Szasz, O. (2013) Renewing Oncological Hyperthermia-Oncothermia. Open Journal of Biophysics, 3, 245-252. https://doi.org/10.4236/ojbiphy.2013.34030

[13] Szasz, A., Iluri, N. and Szasz, O. (2013) Local Hyperthermia in Oncology-To Choose or Not to Choose? In: Huilgol, N., Ed., A Chapter in Book: Hyperthermia, InTech, London.

[14] Szasz, O. and Szasz, A. (2014) Oncothermia-Nano-Heating Paradigm. Journal of Cancer Science and Therapy, 6, 117-121. https://doi.org/10.4172/1948-5956.1000259

[15] Szasz, A. (2013) Electromagnetic Effects in Nanoscale Range. In: Shimizu, T. and Kondo, T., Eds., Cellular Response to Physical Stress and Therapeutic Applications, Chapter 4, Nova Science Publishers, Inc., New York.

[16] Mole, R.H. (1953) Whole Body Irradiation: Radiobiology or Medicine? The British Journal of Radiology, 26, 234-241. https://doi.org/10.1259/0007-1285-26-305-234

[17] Formenti, S.C. and Demaria, S. (2009) Systemic Effects of Local Therapy. The Lancet Oncology, 10, 718-726. https://doi.org/10.1016/S1470-2045(09)70082-8

[18] de la Cruz-Merino, L., Illescas-Vacas, A., Grueso-López, A., Barco-Sánchez, A. and Míguez-Sánchez, C. (2014) Radiation for Awakening the Dormant Immune System, a Promising Challenge to Be Explored. Frontiers in Immunology, 5, 102. https://doi.org/10.1016/S1470-2045(09)70082-8

[19] Kaur, P. and Asea, A. (2012) Radiation-Induced Effects and the Immune System in Cancer. Frontiers in Oncology, 2, 191. https://doi.org/10.3389/fonc.2012.00191

[20] Waitz, R. and Solomon, S.B. (2009) Can Local Radiofrequency Ablation of Tumors Generate Systemic Immunity against Metastatic Disease? Radiology, 251, 1-2. https://doi.org/10.1148/radiol.2511082215 
[21] Keisari, Y. (2013) Tumor Ablation: Effects on Systemic and Local Anti-Tumor Immunity and on Other Tumor-Microenvironment Interactions. Vol. 5, Springer, Dordrecht.

[22] Fiorentini, G., Yoon, S.M., Okamoto, Y., andocs, G., Baronzio, G.F., Schwarz, L., Balogh, L. and Szasz, A. (2013) Abscopal Effect: New Perspectives in Oncothermia. Oncothermia Journal, 7, 279-281.

[23] Meggyeshazi, N., andocs, G., Balogh, L., Balla, P., Kiszner, G., Teleki, I., Jeney, A. and Krenacs, T. (2014) DNA Fragmentation and Caspase-Independent Programmed Cell Death by Modulated Electrohyperthermia. Strahlentherapie und Onkologie, 190, 815-822. https://doi.org/10.1007/s00066-014-0617-1

[24] Andocs, G., Meggyeshazi, N., Balogh, L., Spisak, S., Maros, M.E., Balla, P., Kiszner, G., Teleki, I., Kovago, Cs. and Krenacs, T. (2014) Upregulation of Heat Shock Proteins and the Promotion of Damage-Associated Molecular Pattern Signals in a Colorectal Cancer Model by Modualted Electrohyperthermia. Cell Stress and Chaperones, 20, 37-46. https://doi.org/10.1007/s12192-014-0523-6

[25] Tsang, Y.W., Huang, C.C., Yang, K.L., Chi, M.S., Chiang, H.C., Wang, Y.S., Andocs, G., Szasz, A., Li, W.T. and Chi, K.H. (2015) Improving Immunological Tumor Microenvironment using Electro-Hyperthermia Followed by Dendritic Cell Immunotherapy. BMC Cancer, 15, 708. https://doi.org/10.1186/s12885-015-1690-2

[26] Szasz, A., Szasz, O. and Szasz, N. (2006) Physical Background and Technical Realization of Hyperthermia. In: Baronzio, G.F. and Hager, E.D., Eds., Hyperthermia in Cancer Treatment. A Primer, Springer Verlag, Berlin, 27-59.

[27] Granmt, D. (1904) The Galvano-Cautery in the Treatment of Intra-Laryngeal Growths. The Journal of Laryngology Rhinology and Ontology, 19, 294-297. https://doi.org/10.1017/S1755146300174633

[28] Short History of Bioelectrics. http://www.pulsedpower.eu/bioelectrics/bio_02_main.html

[29] Kratzer, G.L. and Onsanit, T. (2007) Fulguration of Selected Cancers of the Rectum: Report of 27 Cases. Diseases of Colon and Rectum, 15, 431-435. https://doi.org/10.1007/BF02642647

[30] Nordenstrom, B.W.E. (1983) Biologically Closed Electric Circuits: Clinical Experimental and Theoretical Evidence for an Additional Circulatory System. Nordic Medical Publications, Stockholm.

[31] Nordenstrom, B.W.E. (1998) Exploring BCEC-Systems, (Biologically Closed Electric Circuits). Nordic Medical Publications, Stockholm.

[32] Watson, B.W. (1991) Reappraisal: The Treatment of Tumors with Direct Electric Current. Medical Science Research, 19, 103-105.

[33] Samuelsson, L., Jonsson, L. and Stahl, E. (1983) Percutaneous Treatment of Pulmonary Tumors by Electrolysis. Radiologie, 23, 284-287.

[34] Miklavcic, D., Sersa, G., Kryzanowski, M., Novakovic, S., Bobanovic, F., Golouh, R. and Vodovnik, L. (1993) Tumor Treatment by Direct Electric Current, Tumor Temperature and $\mathrm{pH}$, Electrode Materials and Configuration. Journal of Bioengineering and Bioelectronics, 30, 209-220. https://doi.org/10.1016/0302-4598(93)80080-E

[35] Urano, M. and Douple, E. (1992) Interstitial Hyperthermia: Physics, Biology And Clinical Aspects (Hyperthermia and Oncology, Vol. 3). VSP BV, Utrecht.

[36] Ellis, L.M., Curley, S.A. and Tanabe, K.K. (2004) Radiofrequency Ablation of Cancer. Springer Verlag, New York, Berlin. 
[37] Schmidt, D., Trubenbach, J., Konig, C.W., Brieger, J., Duda, S., Claussen, C.D. and Pereira, P.L. (2003) Radiofrequency Ablation ex Vivo: Comparison of the Efficacy Impedance Control Mode versus Manual Control Mode by using Internally Cooled Clustered Electrode. Rofo Fortschr Geb Rontgenstr Neuen Bildgeb Verfahr, 175, 967-972. https://doi.org/10.1055/s-2003-40436

[38] Faes, T.J.C., van der Meij, H.A., de Munck, J.C. and Heethaar, R.M. (1999) The Electric Resistivity of Human Tissues. Physiological Measurement, 20, R1-R10. https://doi.org/10.1088/0967-3334/20/4/201

[39] Rao, N.N. (2004) Elements of Engineering Electromagnetics. Pearson-Prentice Hall International, Pearson Education Inc., London.

[40] Slosarek, K., Konopacka, M., Rogolinski, J., Latocha, M. and Sochanik, A. (2005) Effect of Depth on Radiation-Induced Cell Damage in a Water Phantom. Reports of Practical Oncology and Radiotherapy, 10, 37-41. https://doi.org/10.1016/S1507-1367(05)71080-4

[41] Vincze, Gy., Szigeti, Gy., andocs, G. and Szasz, A. (2015) Nanoheating without Artificial Nanoparticles. Biology and Medicine, 7, 249.

[42] Andocs, G., Rehman, M.U., Zhao, Q.L., Papp, E., Kondo, T. and Szasz, A. (2015) Nanoheating without Artificial Nanoparticles Part II. Experimental Support of the Nanoheating Concept of the Modulated Electro-Hyperthermia Method, using U937 Cell Suspension Model. Biology and Medicine, 7, 1-9. https://doi.org/10.4172/0974-8369.1000247

[43] Andocs, G., Rehman, M.U., Zhao, Q.-L., Tabuchi, Y., Kanamori, M. and Kondo, T. (2016) Comparison of Biological Effects of Modulated Electro-Hyperthermia and Conventional Heat Treatment in Human Lymphoma U937 Cell. Cell Death Discovery, 2, Article No. 16039. https://doi.org/10.1038/cddiscovery.2016.39

[44] Yang, K.L., Huang, C.C., Chi, M.S., Chiang, H.C., Wang, Y.S., andocs, G., Wang, H.E. and Chi, K.H. (2016) In Vitro Comparison of Conventional Hyperthermia and Modulated Electro-Hyperthermia. Oncotarget, 7, 84082-84092.

[45] Vincze, Gy., Szasz, O. and Szasz, A. (2015) Generalization of the Thermal Dose of Hyperthermia in Oncology. Open Journal of Biophysics, 5, 97-114. https://doi.org/10.4236/ojbiphy.2015.54009

[46] Andocs, G., Renner, H., Balogh, L., Fonyad, L., Jakab, C. and Szasz, A. (2009) Strong Synergy of Heat and Modulated Electro-Magnetic Field in Tumor Cell Killing, Study of HT29 Xenograft Tumors in a Nude Mice Model. Strahlentherapie und Onkologie, 185, 120-126. https://doi.org/10.1007/s00066-009-1903-1

[47] Nagy, G., Meggyeshazi, N. and Szasz, O. (2013) Deep Temperature Measurements in Oncothermia Processes. Conference Papers in Medicine, 2013, Article ID: 685264. http://www.hindawi.com/archive/2013/685264/

[48] Balogh, L., Polyak, A., Postenyi, Z., Kovacs-Haasz, V., Gyongy, M. and Thuroczy, J. (2016) Temperature Increase Induced by Modulated Electrohyperthermia (Oncothermia) in the Anesthetized Pig Liver. Journal of Cancer Research and Therapeutics, 12, 1153-1159.

http://www.cancerjournal.net/article.asp?issn=0973-1482; year=2016; volume=12;iss

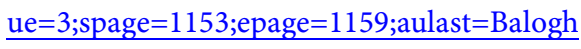

[49] Szasz, A., Szasz, N. and Szasz, O. (2010) Oncothermia-Principles and Practices. Springer Science, Heidelberg. http://www.springer.com/gp/book/9789048194971

[50] Gadaleta-Caldarola, G., Infusino, S., Galise, I., Ranieri, G., Vinciarelly, G., Fazio, V., Divella, R., Daniele, A., Filippelli, G. and Gadaleta, C.D. (2014) Sorafenib and Locoregional Deep Electro-Hyperthermia in Advanced Hepatocellular Carcinoma. A 
Phase II Study. Oncology Letters, 8, 1783-1787.

http://www.ncbi.nlm.nih.gov/pmc/articles/PMC4156230/ https://doi.org/10.3892/ol.2014.2376

[51] Hager, E.D., Dziambor, H., Höhmann, D., Gallenbeck, D., Stephan, M. and Popa, C. (1999) Deep Hyperthermia with Radiofrequencies in Patients with Liver Metastases from Colorectal Cancer. Anticancer Research, 19, 3403-3408. http://www.ncbi.nlm.nih.gov/pubmed/10629627

[52] Szasz, O. and Szasz, A. (2016) Heating, Efficacy and Dose of Local Hyperthermia. Open Journal of Biophysics, 6, 10-18. http://www.scirp.org/journal/PaperInformation.aspx?paperID=62874 https://doi.org/10.4236/ojbiphy.2016.61002

[53] Szasz, O., Andocs, G. and Meggyeshazi, N. (2013) Oncothermia as Personalized Treatment Option. Conference Papers in Medicine, 2013, Article ID: 2941364. http://www.hindawi.com/archive/2013/941364/

[54] Hegyi, G., Szigeti, G.P. and Szasz, A. (2013) Hyperthermia versus Oncothermia: Cellular Effects in Complementary Cancer Therapy. Evidence-Based Complementary and Alternative Medicine, 2013, Article ID: 672873.

http://www.hindawi.com/journals/ecam/2013/672873/ https://doi.org/10.1155/2013/672873

[55] Baronzio, G., Parmar, G., Ballerini, M., Szasz, A., Baronzio, M. and Cassutti, V. (2014) A Brief Overview of Hyperthermia in Cancer Treatment. Journal of Integrative Oncology, 3, 1. https://doi.org/10.4172/2329-6771.1000115

[56] Szasz, A. (2015) Bioelectromagnetic Paradigm of Cancer Treatment Oncothermia. In: Rosch, P.J., Ed., Bioelectromagnetic and Subtle Energy Medicine, CRC Press, Taylor \& Francis Group, 323-336.

[57] Lee, D. and Szasz, A. (2016) Heat Therapy in Oncology, New Paradigm in Electro-Hyperthermia. Kim Jei Min Publishing.

[58] Hegyi, G., Szasz, O. and Szasz, A. (2013) Oncothermia: A New Paradigm and Promising Method in Cancer Therapies. Acupuncture \& Electro-Therapeutics Research, 38, 161-197. http://www.ncbi.nlm.nih.gov/pubmed/24494322

[59] Meggyeshazi, N., Andocs, G., Spisak, S. and Krenacs, T. (2013) Early Changes in mRNA and Protein Expression Related to Cancer Treatment by Modulated Electro-Hyperthermia. Conference Papers in Medicine, 2013, Article ID: 249563. http://www.hindawi.com/archive/2013/249563/

[60] Meggyeshazi, N., Andocs, G. and Krenacs, T. (2013) Programmed Cell Death Induced by Modulated Electro-Hyperthermia. Conference Papers in Medicine, 2013, Article ID: 187835. http://www.hindawi.com/archive/2013/187835/

[61] Szasz, O., Szasz, A.M., Minnaar, C. and Szasz, A. (2017) Heating Preciosity-Trends in Modern Oncological Hyperthermia. Open Journal of Biophysics, 7, 116-144. http://www.scirp.org/journal/PaperInformation.aspx?PaperID=77458 https://doi.org/10.4236/ojbiphy.2017.73010 